\title{
Determinants of HIV Status Disclosure among Adolescents in Bondo Sub-county of Siaya County in Kenya
}

\author{
J. Obiero $^{1 *}$, D. Onguru ${ }^{1}$, S. Ogolla ${ }^{1} \&$ E. Mboya ${ }^{2}$ \\ ${ }^{I}$ Department of Public Health, School of Health Sciences, Jaramogi Oginga Odinga University of Science and Technology, Bondo, Kenya. ${ }^{2}$ Department of \\ Strategic Information, Ministry of Health, Siaya County. Email: juliusizahh@yahoo.com ${ }^{I^{*}}$
}

DOI: http://doi.org/10.46382/MJBAS.2021.5301

Copyright: $\odot 2021 \mathrm{~J}$. Obiero et al. This is an open access article distributed under the terms of the Creative Commons Attribution License, which permits unrestricted use, distribution, and reproduction in any medium, provided the original author and source are credited.

Background: With the widespread use of highly active antiretroviral therapy, the epidemic of HIV has evolved into a chronic disease. HIV is extremely stigmatizing, resulting in highly emotionally charged responses to disclosure. World Health Organization (WHO) recommends that children should be informed of their HIV status at ages of 6 to 12 years and full disclosure at about 8 to 10 years. Disclosure process is much more difficult when the person being disclosed to is an adolescent. However, disclosure of HIV to a child should be an ongoing process that may last several years depending on the cognitive development of the child.

Methods: This study investigated the determinants of HIV status disclosure among HIV infected adolescents. A total of 209 HIV infected adolescents (10-19 years) who have been on treatment for at least six months, and are taking lifelong anti-retroviral therapy from Bondo County Hospital, Got Agulu and Uyawi Sub County Hospital in Bondo Sub County were enrolled. Simple random sampling was employed in selecting the adolescents. Data was collected using a structured questionnaire. Quantitative data was analysed using both descriptive and inferential statistics while statistical tests including Pearson Correlation analysis and multiple linear regression were used to test the hypotheses.

Results: Findings on the overall parental perceptions regarding risks and benefits of disclosure and disclosure of HIV status to adolescents show tha $180(86.12 \%)$ of the respondents had a negative attitude compared to $29(13.88 \%)$ who held a positive attitude. $122(58.37 \%)$ of the respondents believed that overall availability and quality of counselling was moderate. $10(4.78 \%)$ of the respondents believed that the overall availability and quality of counselling was high. Quality services and perception of the parents have been found to be good predictors of disclosure of HIV status among the newly diagnosed adolescents in Bondo sub-County, p-value $<0.05$.

Conclusion and recommendation: This study identified quality of service and perception of the parents as the two factors determining the disclosure of HIV status. There is a correlation between the parental perceptions regarding risks and benefits of disclosure and the quality of counselling to parental disclosure of HIV status to adolescents. Therefore the study recommends deliberate efforts to ensure quality service delivery and age specific disclosure counselling to caregivers to equip them with adequate knowledge on disclosure.

Keywords: ART, Disclosure, Infected adolescents, Risks of disclosure, Attitude, Perception, Parents, Counselling, Service delivery, Knowledge.

\section{Introduction}

In 2019, the World Health Organization (WHO) estimated that there were 3.7 million children under 15 years of age living with HIV, while an estimated 580,000 children were newly infected in 2019 alone (1,2). The advent of ART and expanded access to treatment has resulted in more HIV-infected children reaching adolescence and adulthood (3). As HIV-infected children live longer, emerging challenges to pediatric HIV care include supporting adherence to treatment, preventing secondary transmission (4), monitoring drug interactions (5) and promoting overall physical and mental health (6). Disclosure is an important step towards long-term disease management and necessary for the transition from pediatric care into adolescent and adult care settings (7). Kenya is among the countries most affected by HIV/AIDS in the world, with over 1,617,707 (4.9\%) people living with HIV .Among these 105,000(6.4\%) are children under the age of 15 years (8). The prevalence of HIV among young people between the age of $15-24$ years has been shown to stand at 184,700 (9).The prevalence of HIV in Bondo Sub County is at $24.8 \%$ (10). The total number of PLHIV is 17,355 adults over 15 years and 1,266 children under 15 years $(10,11)$. The rate of new infections has dropped by almost $50 \%$ to 20,059 annually (11). Evidence from a recent systematic review shows that the majority of the adolescents less than 19 years living with HIV in resource 
limited settings are not aware of their own HIV status (12). Although the benefits associated with HIV status disclosure are known, the proportion of children who know their HIV status varies, ranging between 0-54\% largely due to caregivers' knowledge about HIV status disclosure and monthly earnings (13).Disclosing the diagnosis of HIV or AIDS to a child or adolescent is controversial and emotionally-charged issue among health workers, parents and caregivers (14). Worldwide, one of the most controversial topics of discussion among families of children and adolescents who are infected with HIV/AIDS is whether or not to tell the child about the child's own diagnosis (vertical disclosure) and if they do, whether or not to allow the child to tell others, known as horizontal disclosure $(15,16)$. Some parents were known to ask healthcare providers and caregivers not to mention the words HIV and AIDS around their school age children.

Noting that HIV/AIDS is a chronic illness and its treatment is life-long, young persons infected with the illness need to know their status and details about their treatment. Without knowing this, problems of adherence to treatment arise, which may predispose these children to problems such as development of drug resistance or treatment failure (17). In addition, for as long as these children or adolescents don't know what they are suffering from, there's the danger of them transmitting the infection to others through, for instance, unprotected sex or sharing of needles for those who are involved in intravenous drug injection and use (18). There is also the problem of negative psychological effects which may arise if the child finds out about their status in an unsupportive way. Children may also miss out on the all-important social support if they are continually kept in the dark about their illness (18). In the light of the above-mentioned developments, parents and guardians have an insurmountable task to disclose the children and adolescent's HIV status to them. Studies relying on caregiver reports in various parts of the world, found great variations in rates of HIV status disclosure to children infected with the disease, ranging from $10 \%$ in some areas to $75 \%$ in others (19-21).

\section{Methodology}

\section{Study design}

This was a cross-sectional, descriptive study using structured questionnaires to gather both qualitative and quantitative data.

\section{Study Setting}

This study was conducted at the HIV comprehensive care clinics (CCC) at Bondo County Hospital, Got Agulu Sub County Hospital and Uyawi Sub County Hospital. The study area lies on the northern shores of Lake Victoria within latitudes $0.0^{\circ} 02^{\prime} \mathrm{N}$ and $0.0^{\circ} 24^{\prime} \mathrm{S}$ and Longitudes $34^{\circ} 0.0^{\prime} \mathrm{E}$ and $34^{\circ} 26^{\prime} \mathrm{E}$. It covers Bondo Sub-County of Siaya County of Kenya. It is divided into three administrative divisions, which are: Maranda, Nyang'oma and Usigu in Bondo Sub-County.

\section{Study Population size and composition}

The Sub County covers an area of 1,972 square kilometers of which 972 square kilometers is land surface while 1,000 square kilometers is covered with the waters of Lake. The total population of Bondo Sub County as at 2016 
was estimated to be 214,541 people according to KNBS 2019 population projection (22) with 100,259 males and 114,282 females. The Sub County is divided into six administrative units: West Yimbo Ward, Central Sakwa Ward, South Sakwa Ward, Yimbo East Ward, West Sakwa Ward North Sakwa Ward.

\section{Target population}

This study targets HIV infected adolescents (10-19 years) who have known their HIV status for at least six months, and are taking lifelong anti-retroviral therapy. Bondo Sub County has a total of 937 adolescents (10-19years) who know their HIV status for at least six months and are taking lifelong anti-retroviral therapy. Of these adolescents, Bondo County Hospital has a total of 241 adolescents, Got Agulu SCH has 96 and Uyawi SCH has 101 (11).

\section{Initiation criteria}

The study included HIV infected adolescents (10-19 years) who knew their HIV status for at least six months (confirmed HIV positive through the national HIV testing guidelines (23)), attended the clinic during the study period and were mentally capable of giving an informed consent or assent. HIV infected adolescents (10-19 years) who were acutely ill or required hospitalization, those who could not give informed consent and those who had no documented parents or caregivers were excluded from the study.

\section{Sampling Procedure}

Simple random sampling for quantitative data for qualitative data was used as described below:

A sampling frame of $438 \mathrm{HIV}$ infected adolescents between the ages of 10 and 19 years from each of the HIV care and treatment clinics in Bondo County Hospital, Got Agulu Sub county Hospital and Uyawi Sub county Hospital was used to enlist 209 adolescents. Random numbers were generated from the computer and tagged to each adolescent. To determine the ideal sample size Yamane (1967) formula was used (24). Participants were provided with two consent/assent forms, one in the local language (Dholuo) and other in the English. Those who are under18 years of age were asked to sign an assent form and then consent was sought from the parent or guardian. A brief demographic questionnaire was administered to all participants. This was followed by an in-depth interview to cover a core set of topics, lasting 45 minutes to an hour.

\section{Data collection procedures}

The interviews were conducted in either English or the local language (Dholuo) depending on the preference of the participant. The interviews were conducted by the principal investigator and a research assistant. All interviews were conducted in a private room dedicated to the study team, with confidentiality assured. Written notes were taken to document any non-verbal cues. The first four interviews that were conducted in the local language (Dholuo) were transcribed in the language of the interview. This was followed by translation of the Dholuo transcripts into English. The English translation was done by a bilingual speaker. After confirming the good quality of transcription and translation, the rest of all the Dholuo interviews were translated simultaneously. All the interviews conducted in the English language were transcribed as such. Each participant was given a unique identification code and all the identifying information was removed. All the demographic information was 
captured using Microsoft Office Excel. Selected respondents were interviewed using an in-depth interview guide under strict confidentiality.

\section{Research instruments}

The interviews were guided by an interview guide with themes arising from a literature search and after consultation with stakeholders including HIV care physicians, nurses and counsellors. The interview guide contained open-ended questions regarding adolescents' ideas about disclosure, about their own disclosure experience and the perceived barriers and facilitators of disclosure to others. The questions were followed by suitable probes to assist and explore the relevant issue. Rapport was established with the participant to assist them to open up. The interview guide was translated into the local language and back translated to ensure validity. The guide was piloted on 2 participants and the weaknesses identified were corrected in the final interview guideline. All the interviews were conducted by the principal investigator and a qualified bilingual research assistant. The interview guide was further facilitated by the use of emotion maps. These are pictures which were designed by a local artist and show a range of different emotions for example sad, happy, afraid, confused etc.

\section{Data analysis}

The quantitative data was analysed using both descriptive and inferential statistics. Descriptive statistics was used to describe and summarize the data inform of charts, tables, frequencies, and percentages. Inferential statistics was used to help make inferences and draw conclusions. Statistical tests including Pearson Correlation analysis and multiple linear regression were used to test the hypotheses. Correlation analysis was used to determine the association between the parental perceptions regarding risks and benefits of disclosure and disclosure of HIV status to children and adolescents and to establish the relationship between the quality of counselling and parental disclosure of HIV status to HIV-infected children and adolescents while multiple linear regression were used to establish the factors determining the disclosure of HIV status among the newly diagnosed adolescents in Bondo sub-County. The Statistical Package for Social Sciences (SPSS) version 22 was used to analyse the data.

\section{Consent}

Consent to participate in the study was sought from the parent/guardian of the child before asking for assent from the child. Participants were informed clearly on the aim, risks, and benefits of the study. Caregivers were interviewed in the absence of their children to minimize chances of exposing the child to some of the questions they were not prepared to answer. To ensure confidentiality, the information collected was kept anonymous by not including the names of the participants and their guardians as well as the names of the treatment centers. Health education and counselling were provided to all guardians and participants approached to participate in this study at the end of each interview/contact.

\section{Ethical Approval}

Ethical clearance and approval to conduct this study was sought from the Board of Postgraduate Studies, JOOUST. Ethical approval of the study was obtained from the Jaramogi Oginga Odinga Teaching and Referral Hospital 
Ethics Review Committee (JOOTRH-ERC) and further authorization obtained from the Bondo Sub County Health Management Team.

\section{Results}

\section{Demographic information of the Adolescents}

The data used in this study was drawn from a population of 209 respondents from three health facilities in Siaya County. Most of the respondents; 126 (60.29\%) were from Bondo County Hospital while 42 (20.1\%) and 41 (19.62\%) were from Got Agulu Sub County Hospital and Uyawi Sub County Hospital, respectively. The sampled respondents were $209(n=209)$. Given that the questionnaires were administered personally by the researcher, it was noted that $100 \%$ of the questionnaires were appropriately filled. Of all the adolescents who were living with HIV and are recipients of care; 91 (43.54\%) were staying with their mothers.

\section{Demographic characteristics of the parent/caregivers}

The findings in the Table 1.1 below shows that a majority of the respondents; 133 (63.64\%) were females while male colleagues accounted for 76(36.36\%). More than half of the respondents; 121 (57.89\%) were from Bondo followed by Uyawi and Got Agulu health facilities representing 37 (17.7\%) and 34 (16.27\%) respectively. In addition, a majority of the respondents; $155(74.16 \%)$ were married. Finally, 174 (83.25\%) of the respondents confirmed that the caregivers had received the caregiver standard package of care education on HIV.

Table 1.1. Demographic characteristics of the Respondents

\begin{tabular}{llr}
\hline Demographic characteristics & Frequency, n= 209 & Percent (\%) \\
\hline Information about the adolescents & & \\
Bondo Sub County Hospital & 126 & 60.29 \\
Got Agulu Sub County Hospital & 42 & 20.10 \\
Uyawi Sub County Hospital & 41 & 19.62 \\
Gender & & \\
Female & 133 & 63.64 \\
Male & 76 & 36.36 \\
Information about the Parent/Caregiver & & \\
Residence & & 0.48 \\
Akala & 1 & 57.89 \\
Bondo & 121 & 0.48 \\
Bumala & 1 & 16.27 \\
Got Agulu & 34 & 1.44 \\
Kisumu & 3 & 0.48 \\
Ndori & 1 & 0.48 \\
Osieko & 1 & 0.48 \\
Rarieda & 1 & 0.48 \\
Seme & 1 &
\end{tabular}




\begin{tabular}{llr} 
Siaya & 2 & 0.96 \\
Ugunja & 1 & 0.48 \\
Usenge & 3 & 1.44 \\
Usigu & 1 & 0.48 \\
Uyawi & 37 & 17.70 \\
Yala & 1 & 0.48 \\
Marital status & & \\
Married & 155 & 74.16 \\
Single & 28 & 13.40 \\
Widowed & 26 & 12.44 \\
Relationship to the adolescent & & \\
Aunt & 28 & 13.40 \\
Brother & 13 & 6.22 \\
Father & 51 & 24.40 \\
Grand father & 5 & 2.39 \\
Grand mother & 3 & 1.44 \\
Mother & 91 & 43.54 \\
Sister & 11 & 5.26 \\
Uncle & 7 & 3.35 \\
Education by care giver on HIV & & 8.25 \\
No & 17 & 8.13 \\
Partially & 18 & 8.61 \\
Yes & 174 & \\
\hline & & \\
\hline
\end{tabular}

According to the findings in Table 1.2, the ratio of Protestants to Catholics is almost 1:1. In addition, a majority of the adolescents; 106 (50.72\%) were females, outweighing their male counterparts accounting for 103 (49.28\%). Most adolescents; 137 (65.55\%) had a primary level of education followed by 67 (32.06\%) whose education level was secondary. The mean age of the adolescents was 15.54 with a standard deviation of 2.64 while the minimum and maximum age was 10 and 19 years respectively.

Table 1.2. Demographic characteristics of the adolescents

\begin{tabular}{lcr}
\hline Information about the adolescent & Frequency, $\mathbf{n = 2 0 9}$ & \% \\
\hline Education & 2 & 0.96 \\
College & 3 & 1.44 \\
No school & 137 & 65.55 \\
Primary & 67 & 32.06 \\
Secondary & & \\
Religion & 102 & 48.80 \\
Catholic & 107 & 51.20 \\
Protestant & & \\
Sex of Adolescent & 106 & 50.72 \\
Female & 103 & 49.28 \\
Male &
\end{tabular}




\section{Adolescents Knowledge of HIV status}

The findings in Table 1.3, shows that a majority of the adolescents; $175(83.73 \%)$ had their HIV disclosure status done and completed whereas $34(16.27 \%)$ had their HIV status disclosure status partially done. In addition, more than half of the HIV disclosures 113 (54.07\%) were done by both the respondents and the counsellor. Furthermore, most adolescents; 187 (89.47\%) reported to know everything about HIV. The mean age at disclosure was 10.23 with a standard deviation of 2.007 with a range of $10-19$ years.

Table 1.3. Adolescent's Knowledge of HIV status

\section{Frequency, $\mathbf{n}=\mathbf{2 0 9}$}

$\%$

\section{Disclosure status}

Partial

Full

\section{Disclosure done by;}

Counselor

Do not Know

Respondent

Respondent \& Counselor

\section{Adolescent's knowledge his/her illness}

Knows everything about HIV

Do not know everything about HIV

Adolescent not told about any illness

16

\section{Psychosocial, cultural, and Service-related factors}

According to table 1.4, 194 respondents accounting to $92.8 \%$ in one way or the other were afraid of getting an angry reaction from the child/adolescent if they knew about their HIV status, 194 (92.84\%) were afraid the child/adolescent would start thinking they would die soon, 194 (92.84\%) were afraid the child/adolescent would start feeling ashamed of themselves, 194 (92.84\%) were afraid the child/adolescent would be rejected by the community, 194 (92.84\%) were afraid the child/adolescent would be isolated by the community and 194 (92.84\%) were afraid the child/adolescent may reveal the secret to other people.

In addition, 198 (94.74\%) of the respondents wanted the child/adolescent to know the truth about the illness while $198(94.74 \%)$ of the respondents were afraid the child/adolescent would hear of the illness from someone else and lose trust in them.202 (96.65\%) of the respondents thought telling the child/adolescent the truth about their HIV status would help to improve the way he/she takes and adheres to his /her medicines for HIV and 175 (83.73\%) thought telling the child/adolescent about HIV infection prevention would help to improve the way he/she takes His /her medicines for HIV. 
Table 1.4. Psychosocial and cultural factors

$\mathbf{N}=\mathbf{2 0 9}$

Yes, n (\%) No, n (\%)

\section{Psychological effects,}

Respondent afraid of getting an angry reaction from the child/adolescent if he knew

$194(92.84) \quad 15,(7.18)$

Respondent afraid the child/adolescent would start thinking they would die soon

Respondent afraid the child/adolescent would start feeling ashamed of themselves

$194(92.84) \quad 15,(7.18)$

\section{Stigma}

Respondent afraid the child/adolescent would be rejected by the community

Respondent afraid the child/adolescent would be isolated by the community

$194(92.84) \quad 15,(7.18)$

\section{Secrecy}

Respondent afraid the child/adolescent may reveal the secret to other people

Respondent want the child/adolescent to know the truth about the illness

Respondent afraid the child/adolescent would hear of the illness from someone else and lose trust in you

$198(94.74) \quad 11(5.26)$

\section{Clinical perceptions}

Respondent think telling the child/adolescent would help to improve the way he/she takes His /her medicines for HIV

\section{Infection prevention concerns}

Respondent think telling the child/adolescent would help to improve the way he/she takes His /her medicines for HIV

\section{Feeling about disclosing to the child/adolescent considering the age}

Most respondents; 187 (89\%) felt the child/adolescent was old enough to know about their HIV status while only $22(11 \%)$ of the respondents believed that the adolescent was not old enough to know.

\section{Feeling of the respondent about keeping the secret}

On keeping the secret about HIV status to the child/adolescent, most respondents; 198(94.74\%) got tired of keeping the secret while 11 (5.26\%) considered it easy to keep it secret.

\section{Parental perceptions regarding risks and benefits of disclosure}

Findings on the overall parental perceptions regarding risks and benefits of disclosure and disclosure of HIV status to children and adolescents show that most respondents; 180 (86.12\%) had a negative attitude compared to only 29 $(13.88 \%)$ of the respondents who held a positive attitude. 


\section{Availability and Quality of Counselling}

The results in the table 1.5 below show that nearly all the respondents; 199 (95.22\%) had been talked to by a clinic counsellor to prepare them for the process of telling the child/adolescent that he/she is HIV-positive while only 10 (4.78\%) had not. In addition, 199 (95.22\%) of the respondents agreed that the counselling the respondent received from the counselor helped them to tell the Child/adolescent that he/she is HIV-positive. In addition, 185 (88.52\%) of the respondents confirmed that there was a private room where the counsellor talked to the respondent. 202 (96.65\%) of the respondents also agreed that the counsellor was polite and patient with the respondent during the discussion.

Table 1.5. Availability and Quality of Counselling

\begin{tabular}{lcc}
\hline Availability and Quality of Counselling, $\mathbf{n = 2 0 9}$ & Yes, $\mathbf{n}(\boldsymbol{\%})$ & No, $\mathbf{n}(\boldsymbol{\%})$ \\
\hline
\end{tabular}

Whether respondent have ever been talked to by a clinic counsellor to prepare you for the process of telling the child/adolescent that he/she is HIV-positive

Whether the counselling the respondent received from this person help you to tell $199(95.22) \quad 10(4.78)$ the Child/adolescent that he/she is HIV-positive

Whether there a private room where the counsellor talked to the respondent

Whether the counsellor was polite and patient with the respondent during the 202 (96.65) discussion

On CTX Prophylaxis

Sexual Activity

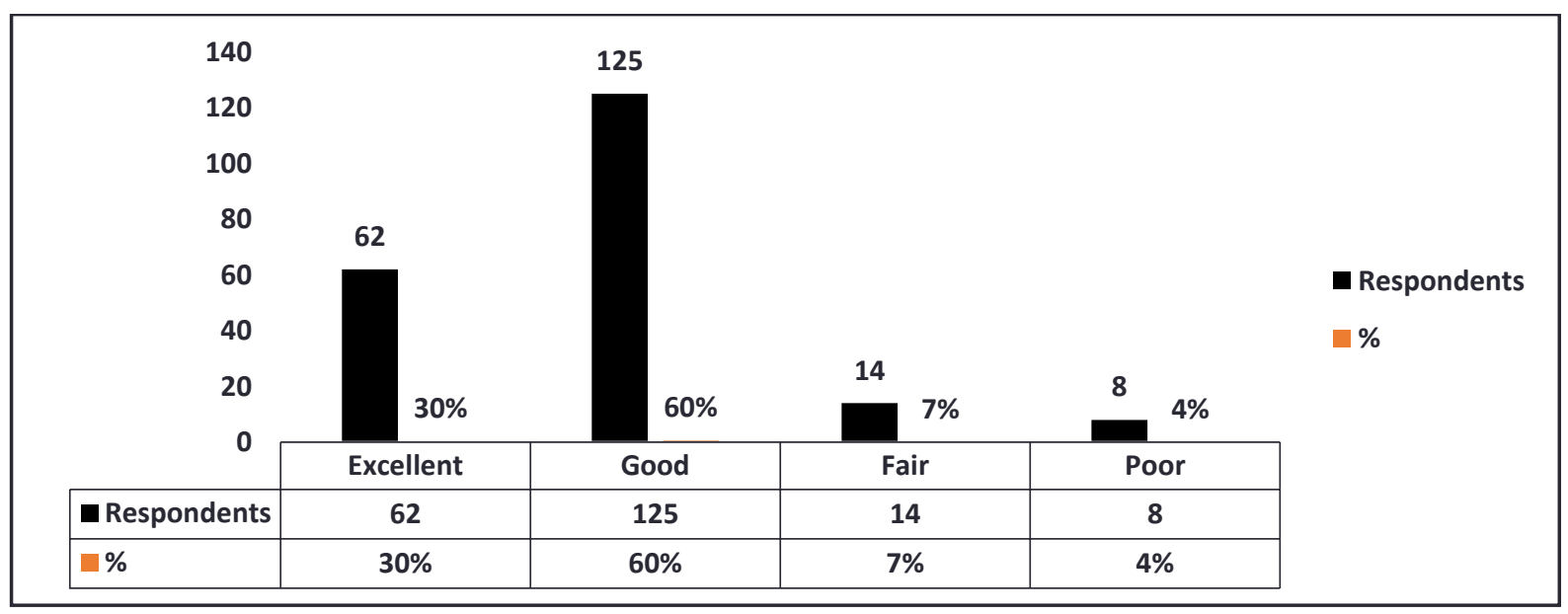

Figure 1.1. Respondent's rating of quality of counselling

$122(58.37 \%)$ of the respondents believed that Overall availability and quality of Counselling was moderate while $77(36.84 \%)$ believed it was low. $10(4.78 \%)$ of the respondents believed that the Overall availability and quality of Counselling was high. The results in Figure 1.1 below indicate that most of the respondents rated the quality of 
services given at the health facilities to be good; $126(60 . \%)$ followed by $61(30 \%)$ who rated it as excellent. However, 8 (4\%) of the respondents rated the quality of services as poor.

\section{Staff who counselled the patients}

In terms of who counselled the respondent, the findings indicate that a majority; 167 (80\%) were counselled by the counsellor while only 42 (20\%) of the respondents were counselled by HCW.

\section{Inferential statistics}

Association between the parental perceptions regarding risks and benefits of disclosure and disclosure of HIV status to children and adolescents

The Pearson Product-Moment correlation result indicates a weak negative correlation between the parental perceptions regarding risks and benefits of disclosure and disclosure of HIV status to children and adolescents. In addition, the analysis also revealed that this relationship is significant $(r=-0.236, p$-value $=0.001<0.05)$.

Table 1.6. Correlations

\begin{tabular}{llcc}
\hline & & Perception of parents & Disclosure status \\
\hline Perception of the & Pearson Correlation & 1 & $-0.236^{* *}$ \\
parents & Sig. (2-tailed) & 209 & 0.001 \\
& $\mathrm{~N}$ & $-0.236^{* *}$ & 209 \\
\hline Disclosure status & Pearson Correlation & 0.001 & 1 \\
& Sig. (2-tailed) & 209 & 209 \\
& $\mathrm{~N}$ & & \\
\end{tabular}

**. Correlation is significant at the 0.01 level (2-tailed)

Relationship between the quality of counselling and parental disclosure of HIV status to HIV-infected children and adolescents

The Pearson Product-Moment correlation result indicates a weak positive correlation between the quality of counselling and parental disclosure of HIV status to HIV-infected children and adolescents. In addition, the analysis also revealed that this relationship is significant $(\mathrm{r}=0.180, \mathrm{p}$-value $=0.009<0.05)$.

Table 1.7. Correlations

\section{Quality services $\quad$ Perception of parents}

\begin{tabular}{llrr}
\hline Quality services & Pearson Correlation & 1 & $0.180^{* *}$ \\
& Sig. (2-tailed) & & 0.009 \\
N & 209 & 209 \\
Disclosure status & Pearson Correlation & $0.180^{* *}$ & 1 \\
& Sig. (2-tailed) & 0.009 & \\
& N & 209 & 209
\end{tabular}

**. Correlation is significant at the 0.01 level (2-tailed) 
Factors determining the disclosure of HIV status among the newly diagnosed adolescents in Bondo sub-County

A multiple regression analysis was also conducted to determine which factors are the best predictors of the disclosure of HIV status among the newly diagnosed adolescents in Bondo sub-County and the results shown in the table below. The results of the model summary indicate the overall adequacy of the model. From the results, the overall adequacy of the model is $21.6 \%$ meaning that the disclosure of HIV status among adolescents living with HIV in Bondo sub-County varies by the factors identified below (sex of the adolescent, education of care giver on HIV, religion of the adolescent, education level of the adolescent, marital status, sex of the caregiver or parent, perception of the parents, disclosure status, facility, age of the adolescent).

Table 1.8. Model Summary

\begin{tabular}{lrrrr}
\hline Model & R & R Square & $\begin{array}{c}\text { Adjusted R } \\
\text { Square }\end{array}$ & \multicolumn{2}{c}{$\begin{array}{c}\text { Std. Error of the } \\
\text { Estimate }\end{array}$} \\
1 & $0.464^{\mathrm{a}}$ & 0.216 & 0.176 & 0.336
\end{tabular}

The results of the table below determine whether the model is significant or not. From the output below, the model is significant, $\mathrm{p}$-value $=0.0005<0.05$.

Table 1.9. ANOVA $^{\mathrm{a}}$

\begin{tabular}{llccccc}
\hline Model & & Sum of Squares & df & Mean Square & F & Sig. \\
\hline & Regression & 6.136 & 10 & 0.614 & 5.440 & $0.000^{\mathrm{b}}$ \\
1 & Residual & 22.333 & 198 & 0.113 & & \\
& Total & 28.469 & 208 & & & \\
\hline
\end{tabular}

a) Dependent Variable: Disclosure status

b) Predictors: (Constant), Sex of Adolescent, Education of care giver on HIV, Religion of the adolescent, Education level of the adolescent, Marital status, Sex of the caregiver or parent, Perception of the parents, Facility, Quality services, Age of Adolescent

From the analysis, two factors that are Quality services and Perception of the parents have been found to be good predictors of disclosure of HIV status among the newly diagnosed adolescents in Bondo sub-County, $\mathrm{p}$-value $<0.05$. For instance, in line with the descriptive statistics, this means that respondents who believed that the Overall Availability and Quality of Counselling is low; 77 (36.84\%) are very likely not to disclose the HIV status to the child than the respondents who believed that the Overall Availability and Quality of Counselling is high; 10 $(4.78 \%)$.

In the findings below, the main outcome is the disclosure status which is also the dependent variable while the Quality services and Perception of the parents are the sampled independent variables. The estimated value in this 
case is the coefficient value and it shows the relationship between the independent and dependent variables. For instance, in the output, the coefficient for Quality services is 0.13 meaning that when the quality services increase by 1 , the disclosure status also increases by $13 \%$. To note, coefficient values which are positive like 0.13 show that the relationship between the Quality services and the disclosure are also positive to mean that when the quality services increase, it would result in an increase in the disclosure status.

Table 1.10. Coefficients ${ }^{\mathrm{a}}$

\begin{tabular}{|c|c|c|c|c|c|c|}
\hline \multicolumn{2}{|c|}{ Model } & \multicolumn{2}{|c|}{$\begin{array}{c}\text { Unstandardized } \\
\text { Coefficients }\end{array}$} & \multirow{2}{*}{$\begin{array}{c}\text { Standardized } \\
\text { Coefficients } \\
\text { Beta }\end{array}$} & \multirow[t]{2}{*}{$\mathbf{t}$} & \multirow[t]{2}{*}{ Sig. } \\
\hline & & B & Std. Error & & & \\
\hline \multirow[t]{11}{*}{1} & (Constant) & 0.960 & 0.235 & & 4.081 & 0.000 \\
\hline & Quality services & 0.130 & 0.058 & -0.197 & -2.249 & 0.026 \\
\hline & Perception of the parents & 0.161 & 0.073 & -0.151 & -2.213 & 0.028 \\
\hline & Facility & -0.020 & 0.033 & -0.044 & -0.622 & 0.535 \\
\hline & Sex of the caregiver or parent & 0.040 & 0.050 & 0.052 & 0.786 & 0.433 \\
\hline & Marital status & -0.040 & 0.035 & -0.076 & -1.161 & 0.247 \\
\hline & Education of care giver on HIV & 0.063 & 0.060 & 0.070 & 1.047 & 0.296 \\
\hline & Education level of the adolescent & 0.013 & 0.034 & 0.035 & 0.397 & 0.692 \\
\hline & Religion of the adolescent & -0.152 & 0.048 & -0.206 & -3.193 & 0.002 \\
\hline & Age of Adolescent & 0.012 & 0.013 & 0.087 & 0.910 & 0.364 \\
\hline & Sex of Adolescent & 0.036 & 0.047 & 0.048 & 0.755 & 0.451 \\
\hline
\end{tabular}

a. Dependent Variable: Disclosure status

\section{Discussion}

Because of the complexity and the on-going nature of parents or guardian's struggle with disclosure issues, counselling support from health providers is critical to help parents or guardians realistically appraise their concerns related to disclosure so that they can access needed support and services (18,25). Even though a majority of the parents or guardians understand the importance of disclosing in order to maximize life and health care options of their children, many parents or guardians require continued support to successfully assess the potential consequences of disclosure and cope with the stress of the disclosure process (26).The fact that the rate of full disclosure was not $100 \%$ in this study shows that parents or guardians may have a critical need for quality health education counselling in order to develop a plan for disclosing to their children and to change their perception towards disclosure in order to cope with reactions of people with negative attitudes about individuals with HIV infection $(26,27)$.

The current study represents the first of its kind in Kenya to explore determinants of HIV status disclosure among adolescents and not how decisions concerning disclosure are made. Many parents or guardians' descriptions of 
their decision to disclose or not reflect weighing benefits and costs of disclosure as well as ways to apply criteria regarding the appropriateness or not of disclosure. However, many of the parents or guardians who had not fully disclosed the HIV status of their children discussed making decisions based on their emotional and intuitive processes as their sole criteria for disclosure. This more clearly reflected their personal appraisal of the negative consequences associated with disclosure than reasoned actions. These parents or guardians were less likely to tell children of their HIV infection as compared to parents or guardians providing other categories of responses like full disclosure.

Past research done in other parts of the world, like the current one, supports the fact that parents or guardians' concerns about risks like stigma and rejection related to disclosing the child's HIV sero-status are not unwarranted $(14,28)$. While these cited studies document parents or guardian's concerns about negative responses such as rejection and abandonment primarily within the context of parents or guardian's relationships, parents or guardians may also fear similar negative consequences associated with disclosure to children or adolescents. The group of parents or guardians that found it comfortable disclosing fully the HIV status to their children or adolescents had markedly different appraisals of the consequences associated with disclosure as compared to parents or guardians who had hesitation at first or disclosed it partially.

These parents or guardians seemed unafraid of potential negative consequences of disclosing their child's HIV status and a number of the parents or guardians actively worked to increase awareness of HIV in their children or adolescents. This belief in the benefits of openness and/or confrontation of HIV-related stigma may have served as a resource for these parents or guardians, reducing the fear of disclosure (29). Conversely, as has been documented elsewhere $(18,30)$, another small group of parents or guardian had not disclosed to their children. This group of parents or guardian had appraised the disclosure process to be too difficult or risky to undertake and engaged in avoidant behaviours to hide their illness. Clinically, avoidant behaviour is associated with a host of negative outcomes including depression and anxiety.

Unlike this study, previous studies conducted on the subject indicate that HIV status disclosure is not a random event. A study on parents or guardians' disclosure patterns to their children showed that mothers disclosed more often to their daughters than their sons (31). The study further established that disclosure was significantly more common among parents or guardians with poor health and stressful life events than those without stressful events. This is one aspect the current study did not examine. In addition, this research and just like previous research have shown that the child's age is an important predictor of whether or not the child would be told about his or her infection $(32,33)$.

The findings in this study have public health implications. The low disclosure rates are suggestive of higher perception of risks than benefits in the study population. Although there may be other explanations, it could be argued that provision of better counselling services is one way of countering risks given that the study was conducted in a healthcare delivery setting. It was not surprising to observe that the younger the child was the more unlikely the parent or guardian would be to disclose the child's HIV status. 'Non-disclosure' was preferred for children of less than 6 years old, 'partial disclosure' for children from age 6 to 10 years, 'partial followed by full 
disclosure' for children from 7 years old or so and 'full disclosure' for children above 10 years. The perceived emotional maturity and intellectual capacity of children should be considered because they are important factors in determining the most suitable time and type of HIV disclosure.

\section{Strengths}

This study has notable strengths. Random sampling, allows the results to influence and direct future research and help us question common assumptions in the field such as, less educated people not wanting to disclose HIV status to children, adults not perceiving a need to talk about HIV to children, Western counselling models being applicable and acceptable for Kenyan African families, and current counselling training models paying sufficient attention to variant Kenyan family structures.

\section{Conclusions}

Despite existence of WHO guideline on HIV status disclosure to HIV-infected children and adolescents, prevalence of disclosure was found to be a challenge in this study and often done later after 10 years of age .This study identified two factors (quality of service and perception of the parents) as good predictors of disclosure of HIV status among the HIV infected adolescents in Bondo Sub County.

This study shows a correlation between the parental perceptions regarding risks and benefits of disclosure and disclosure of HIV status to children and adolescents. Parents with positive perception regarding risk and benefits of disclosure are more likely to disclose successfully and on time. Finally, this study establishes a correlation between the quality of counselling and parental disclosure of HIV status to HIV-infected children and adolescents. When counselling is done well by a trained counsellor and in a private setting, disclosure has been noted to be successful.

\section{Recommendations}

The Ministry of Health through the National AIDS Control Council (NACC), and the National AIDS and STIs Control Program (NASCOP) should develop a policy that ensures routine education of parents or guardians of HIV-infected adolescents on basic caregiver HIV education, as a package of care to support in disseminating the necessary information required for disclosure. They should also review current guidelines to ensure quality service delivery including development of age specific disclosure protocols to facilitate correct choice and time of HIV disclosure to children based on age groups or developmental milestones. The Kenya Association of Counselors (KAPC) should also incorporate a module in HIV disclosure counseling in their curriculum. This will equip adherence counselors with skills needed for provision of on-going help and support to all caregivers with the difficult and distressing task of disclosure.

\section{Abbreviations}

ART: Antiretroviral therapy; STI: Sexually transmitted infection; WHO: World Health; JOOUST: Jaramogi Oginga Odinga University of Science and Technology; JOOTRH: Jaramogi Oginga Odinga Teaching and referral Hospital; HIV: Human immunodeficiency virus; AIDS: Acquired Immune deficiency syndrome. 


\section{Acknowledgements}

The authors are grateful for the assistance provided by the healthcare workers in HIV/AIDS Comprehensive care Centers of Bondo, Uyawi and Usigu health facilities. Special thanks are due to the guardians and the participants for their time and readiness to participate in this study. We are grateful to, Sub County Management team of Bondo and the County Management team of Siaya Kenya, for their support.

\section{Declarations}

\section{Source of Funding}

This research did not receive any grant from funding agencies in the public, commercial, or not-for-profit sectors.

\section{Competing Interests Statement}

The authors declare that they have no conflicts of interest or financial relationship relevant to this manuscript.

\section{Ethical Approval}

Ethical clearance and approval to conduct this study was sought from the Board of Postgraduate Studies, JOOUST. Ethical approval of the study was obtained from the Jaramogi Oginga Odinga Teaching and Referral Hospital Ethics Review Committee (JOOTRH-ERC) and further authorization obtained from the Bondo Sub County Health Management Team.

\section{Consent for publication}

Authors declare that they consented for the publication of this research work.

\section{Availability of data and material}

The datasets analyzed in the current study are available from the corresponding author on reasonable request.

\section{Authors' contributions}

Julius Ooko Obiero originated the research question and conceptualization of the study, review of research instrument, data collection, and analysis as well as writing of the manuscript as part of the requirements For the Award of the Degree of Master of Public Health of Jaramogi Oginga Odinga University of Science And Technology. Dr. Daniel Onguru and Dr. Sidney Ogolla as the supervisors contributed in the conceptualization, development, and design of methodology, data curation, formal analysis, and overall oversight and leadership responsibility for the research activity planning and execution of the study. All authors read and approved the final manuscript. Edward Mboya was involved in data management and analysis.

\section{References}

1. Adults D by the DP on AG for, Research and A- AWG of the O of A, (OARAC) AC. Panel on Antiretroviral Guidelines for Adults and Adolescents. Guidelines for the Use of Antiretroviral Agents in Adults and Adolescents with HIV. Dep Heal Hum Serv [Internet]. 2018; 40 (Build 29393). Available from: https://aidsinfo.nih.gov/ contentfiles/ lvguidelines/adultandadolescentgl.pdf 
Mediterranean Journal of Basic and Applied Sciences (MJBAS)

Volume 5, Issue 3, Pages 01-17, July-September 2021

2. South African National Department of Health. 2019 ART Clinical Guidelines. 2019; (May).

3. Khan AU, Choudhary A, Barodiya P. Abhinav National Monthly Refereed Journal of Research in Impact of art on child development and Abhinav National Monthly Refereed Journal of Research In. 2015; 4(5): 1-5.

4. Dellar RC, Dlamini S, Karim QA. Adolescent girls and young women: Key populations for HIV epidemic control. J Int AIDS Soc. 2015; 18(2): 64-70.

5. Pilgrim NA, Okal J, Matheka J, Mukui I, Kalibala S. Challenges to and opportunities for the adoption and routine use of early warning indicators to monitor pediatric HIV drug resistance in Kenya. BMC Pediatr. 2018.

6. Meyers T, Moultrie H, Naidoo K, Cotton M, Eley B, Sherman G. Challenges to pediatric HIV care and treatment in South Africa. J Infect Dis. 2007; 196 (Suppl. 3).

7. Hayfron-Benjamin A, Obiri-Yeboah D, Ayisi-Addo S, Siakwa PM, Mupepi S. HIV diagnosis disclosure to infected children and adolescents; Challenges of family caregivers in the Central Region of Ghana. BMC Pediatr. 2018; 18(1): 1-11.

8. National AIDS and STI Control Programme. Kenya HIV Estimates 2018. 2018; 1-28.

9. (NASCOP) NA and SCP, Ministry of Health K. Kenya Population-based HIV Impact Ass. (Kenphia) 2018.

10. Siaya County Health Management Team. Siaya County HIV and AIDS strategic plan 2016-2019.

11. Kenya Ministry of Health by D. Kenya Health Information System (KHIS) for Aggregate reporting and analysis. [Internet]. [cited 2021 Aug 16]. Available from: https://hiskenya.org/dhis-web-commons/security /login.action?failed=true.

12. Nabunya P, Byansi W, Sensoy Bahar O, McKay M, Ssewamala FM, Damulira C. Factors Associated With HIV Disclosure and HIV-Related Stigma Among Adolescents Living With HIV in Southwestern Uganda. Front Psychiatry. 2020 Jul 31; 0:772.

13. Nzota MS, Matovu JKB, Draper HR, Kisa R, Kiwanuka SN. Determinants and processes of HIV status disclosure to HIV - infected children aged 4 to 17 years receiving HIV care services at Baylor College of Medicine Children's Foundation Tanzania, Centre of Excellence (COE) in Mbeya: A cross-sectional study. BMC Pediatr [Internet]. 2015; 15(1): 1-9. Available from: http://dx.doi.org/10.1186/s12887-015-0399-3.

14. Ubesie AC, Iloh KK, Emodi IJ, Ibeziako NS, Obumneme-Anyim IN, Iloh ON, et al. HIV status disclosure rate and reasons for non-disclosure among infected children and adolescents in Enugu, southeast Nigeria. Sahara J. 2016; 13(1): 136-41.

15. BF S, GA B, LS W, HB B. When children tell their friends they have AIDS: possible consequences for psychological well-being and disease progression. Psychosom Med [Internet]. 2000 [cited 2021 Aug 16]; 62(2): 238-47. Available from: https://pubmed.ncbi.nlm.nih.gov/10772404.

16. Gyamfi E, Okyere P, Enoch A, Appiah-Brempong E. Prevalence of, and barriers to the disclosure of HIV status to infected children and adolescents in a district of Ghana. BMC Int Health Hum Rights. 2017; 17(1): 1-8.

17. NASCOP. Kenya-ARV-Guidelines-2018-Final_20 $0^{\text {th }}$ Aug 2018., 217: 6. 
Mediterranean Journal of Basic and Applied Sciences (MJBAS)

Volume 5, Issue 3, Pages 01-17, July-September 2021

18. E G, P O, E A-B, RO A, KA M. Benefits of Disclosure of HIV Status to Infected Children and Adolescents: Perceptions of Caregivers and Health Care Providers. J Assoc Nurses AIDS Care [Internet]. 2015 Nov 1 [cited 2021 Aug 16]; 26(6): 770-80. Available from: https://pubmed.ncbi.nlm.nih.gov/26324523.

19. Madiba S. Caregivers Lack of Disclosure Skills Delays Disclosure to Children with Perinatal HIV in Resource-Limited Communities: Multicenter Qualitative Data from South Africa and Botswana. Nurs Res Pract. 2016; 2016: 1-7.

20. Exavery A, Charles J, Barankena A, Kuhlik E, Mubyazi GM, Kyaruzi C, et al. Accelerating caregivers' HIV status disclosure to community-based lay social welfare volunteers in Tanzania. AIDS Res Ther [Internet]. 2021; 18(1): 1-14. Available from: https://doi.org/10.1186/s12981-021-00332-4.

21. Kiwanuka J, Haberer JE. Caregiver perceptions and motivation for disclosing or concealing the diagnosis of HIV infection to children receiving HIV care in Mbarara, Uganda: A qualitative study. PLoS One. 2014.

22. KNBS. 2019 Kenya Population and Housing Census Volume IV: Distribution of Population by SocioEconomic Characteristics. 2019.

23. Aids N, Programme STIC. The Kenya HIV Testing. 2015.

24. Yamane T (1967). Statistics: An Introductory Analysis, 2nd Edition, New York: Harper and Row. [Internet]. [cited 2021 Aug 21]. Available from: http://www.sciepub.com/reference/180098.

25. ICAP. Providing disclosure counseling and support the disclosure process : A developmental approach, 1-20. 26. Glaser E. Disclosure of HIV Status Toolkit for Pediatric and Adolescent Populations. Elizab Glas Pediatr AIDS Found Washingt DC. 2016; 1-74.

27. Baker AN, Bayer AM, Kolevic L, Najarro L, Viani RM, Deville JG. Child, Caregiver, and Health Care Provider Perspectives and Experiences Regarding Disclosure of HIV Status to Perinatally Infected Children in Lima, Peru. J Int Assoc Provid AIDS Care. 2018; 17:1-10.

28. Vreeman RC, Scanlon ML, Mwangi A, Turissini M, Ayaya SO, Tenge C, et al. A cross-sectional study of disclosure of HIV status to children and adolescents in Western Kenya. PLoS One. 2014; 9(1): 1-10.

29. Odiachi A. The Impact of Disclosure on Health and Related Outcomes in Human Immunodeficiency Virus-Infected Children: A Literature Review. Front Public Heal. 2017 Aug 30; 5.

30. Jemma Hogwood 1, Tomás Campbell SB. I wish I could tell you but I can't: adolescents with perinatally acquired HIV and their dilemmas around self-disclosure - PubMed.

31. Lee B, Oberdorfer P. Risk-taking behaviors among vertically HIV-infected adolescents in northern Thailand. J Int Assoc Physicians AIDS Care. 2009; 8(4): 221-8.

32. Nöstlinger C, et al., Factors influencing social self-disclosure among adolescents living with HIV in Eastern Africa. AIDS Care - Psychol Socio-Medical Asp AIDS/HIV, 2015 Nov 2; 27: 36-46.

33. Mugo C, Seeh D, et al. Association of experienced and internalized stigma with self-disclosure of HIV status by youth living with HIV. AIDS Behav. 2021 Jul 1; 25(7): 2084-93. 